\title{
Kajian Perbandingan Komposisi Kimia, Sifat Mekanik dan Ketahanan Aus terhadap Baja Perkakas AISI D2 pada Aplikasi DIES
}

\author{
Setiani Ibrahim $^{1 *}$ \\ ${ }^{1}$ Program Studi Teknologi Pengelasan dan Fabrikasi, Fakultas Vokasi, Institut Teknologi dan Sains Bandung \\ ${ }^{1}$ Corresponding author: ibrahimsetiani@yahoo.com
}

\begin{abstract}
Abstrak. Material dies yang digunakan dalam proses stamping harus memiliki kekerasan, ketangguhan, ketahanan aus dan umur pakai yang optimal, untuk menghasilkan perpaduan sifat tersebut diperlukan pemilihan material dies dan proses perlakuan panas yang tepat. Pemilihan material merupakan faktor terpenting untuk mendapatkan umur pakai yang tinggi sehingga dapat mengoptimalkan proses produksi. Salah satu material yang dapat digunakan sebagai dies adalah material baja perkakas AISI D2. Pada penelitian ini di gunakan tiga jenis material baja perkakas AISI D2 dari tiga distributor berbeda, metoda penentuan material baja perkakas AISI D2 yang tepat dilakukan berdasarkan analisis dan sifat mekanik yang dihasilkan setelah proses perlakuan panas. Material yang memiliki ketahanan aus yang tinggi merupakan material yang memiliki struktur mikro martensit temper dengan primary carbide dan small secondary carbide yang dihasilkan setelah proses tempering yang dipengaruhi oleh komposisi kimianya.
\end{abstract}

Keywords: AISI D2 tool steel, Heat Treatment, Karbida

\section{Pendahuluan}

Proses stamping membutuhkan material baja perkakas jenis AISI D2 dengan kandugan krom dan karbon yang tinggi untuk mendapatkan ketahanan aus yang optimal. Material baja perkakas ini digunakan sebagai dies dalam proses stamping. Material dies yang digunakan dalam proses stamping harus memiliki kekerasan, ketangguhan dan ketahanan aus yang tinggi [1]. Selain itu material yang digunakan sebagai dies harus mudah di machining dan memiliki umur pakai yang panjang agar tidak menghambat proses produksi. Material baja perkakas AISI D2 banyak diproduksi di Asia dan Eropa. Negara produsen di Asia antara lain; China, Korea, Jepang dan India. Dies yang menggunakan material dari produsen tertentu sering kali megalami cracking bahkan fracture pada saat produksi, sehingga menghambat proses produksi.

Tabel 13. Komposisi Kimia dan Nilai C eq (JIS)

\begin{tabular}{|l|c|c|c|c|c|c|c|c|c|c|}
\hline \multirow{2}{*}{ Grade } & Kode & \multicolumn{10}{|c|}{ Komposisi Kimia } \\
\cline { 3 - 11 } & Spesimen & $\mathrm{C}$ & $\mathrm{Mn}$ & $\mathrm{Si}$ & $\mathrm{Cr}$ & $\mathrm{Ni}$ & $\mathrm{Mo}$ & $\mathrm{V}$ & $\mathrm{Fe}$ & C eq \\
\hline OCR12VM & C1-CC & $\mathbf{1 . 1 0 3}$ & 0.370 & 0.84 & $\mathbf{8 . 2 5}$ & 0.21 & 2.299 & 0.497 & $\mathrm{Bal}$ & $\mathbf{3 . 4 6 5 0}$ \\
\hline STD 11 & K1-CC & $\mathbf{1 . 4 6 9}$ & 0.267 & 0.21 & $\mathbf{1 1 . 6 4}$ & 0.19 & 0.873 & 0.270 & $\mathrm{Bal}$ & $\mathbf{4 . 1 1 0 3}$ \\
\hline QC 11 & J 1-CC & $\mathbf{1 . 4 1 6}$ & 0.350 & 0.21 & $\mathbf{1 1 . 1 2}$ & 0.16 & 0.846 & 0.203 & Bal & $\mathbf{3 . 9 3 7 1}$ \\
\hline
\end{tabular}

Pada penelitian ini, akan dianalisis sifat-sifat material baja perkakas AISI D2 berdasarkan distributor yang memproduksiya. Selanjutnya akan dikaji ketahanan aus dari masing-masing material baja perkakas setelah melalui proses perlakuan panas. 


\section{Metodologi}

Dilakukan pengumpulan data mengenai stamping dies, kemudian dilakukan pemeriksaan struktur mikro [2], pengujian kekerasan micro vickers [3], pemeriksaan komposisi kimia [4] dan pengujian impak [5] pada material as-received dan dilakukan pemeriksaan struktur mikro pada bagian surface dan cross section, pengujian kekerasan micro vickers, pengujian impak dan pengujian aus.

\section{Data dan Pembahasan}

\subsection{Material}

Spesimen As-Received merupakan spesimen yang telah mengalami proses annealed setelah melalui serangkaian proses steel making pemeriksaan komposisi kimia pada spesimen As-Received dilakukan untuk membandingkan komposisi kimia pada katalog material dan standar JIS [6] dengan hasil pemeriksaan komposisi kimia secara kuantitatif, menggunakan OES (Optical Emission Spectroscopy) [7] dan untuk menghitung Carbon Equivalent (C eq), seperti pada Tabel 13. Sedangkan proses perlakuan panas yang dilakukan dapat dilihat pada Gambar 16.

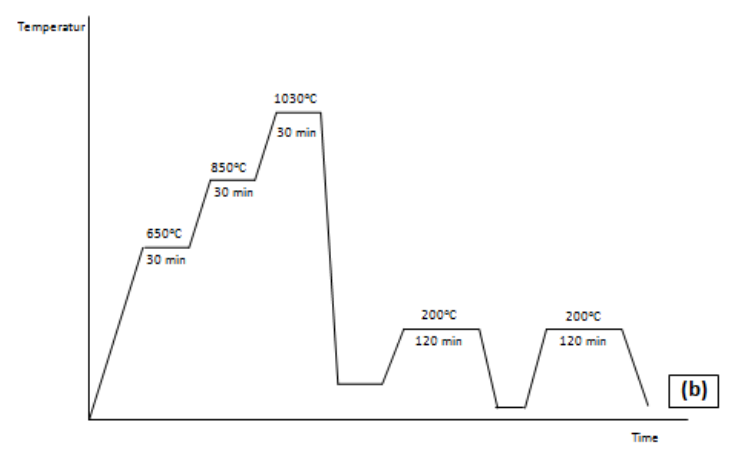

Gambar 16. Proses Perlakuan Panas

\subsection{Analisis Pemeriksaan Struktur Mikro}

Pemeriksaan struktur mikro dilakukan pada annealed conditions (As-Received) untuk mengetahui proses yang terjadi sebelumnya dan treated conditions atau setelah proses perlakuan panas untuk melihat perbedaan morfologi dan fasa yang terbentuk.

Pemeriksaan struktur mikro as-received bertujuan untuk mengetetahui fasa yang terbentuk setelah proses annealed, setelah diamati di bawah optical microscope, fasa yang terbentuk adalah pearlit $\left(\alpha+\mathrm{Fe}_{3} \mathrm{C}\right)$ dengan warna hitam berbintik yang halus berserabut dan karbida berwarna putih terang dengan panjang karbida 2-8 kali dari lebarnya yang mengikuti arah proses rolling, yang terbentuk selama proses solidifikasi, yang terdiri dari primary carbide dan secondary carbide, distribusi primary carbide tidak seragam dan cenderung berkumpul pada satu tempat sedangkan distribusi secondary carbide lebih seragam.

Pemeriksaan struktur mikro Treated juga bertujuan untuk mengetahui fasa yang terbentuk setelah proses perlakuan panas. Karbida yang terbentuk setelah proses perlakuan panas, terutama setelah dilakukan proses temper, terdiri dari primary carbide, berukuran $>5 \mu \mathrm{m}$ dan secondary carbide yang terbagi kedalam dua tipe, yaitu large secondary carbide berukuran 1-5 $\mu \mathrm{m}$ dan small secondary carbide berukuran $<1 \mu \mathrm{m}$. Selain dipengaruhi oleh komposisi kimia masing-masing spesimen, terbentuknya karbida juga dipengaruhi oleh proses perlakuan panas, terutama pemilihan temperatur pada proses temper [8].

Pada saat proses temper, jumlah dislokasi dan distorsi lattice berkurang dan akan memberikan driving force pada karbon dan unsur paduan lainnya untuk berdifusi sehingga terjadi pengintian small secondary carbide. [7]. Perubahan struktur mikro pada As-Received dan Treated terletak pada ukuran dan jumlah coarse primary carbide. Setelah proses perlakuan panas (treated) jumlah coarse primary carbide berkurang tetapi jumlah primary carbide bertambah, selain itu ukuran secondary carbide menjadi lebih kecil. Matrix martensit temper pada spesimen treated juga semakin bertambah banyak. 
Pada spesimen J1 As-Received, bagian yang berwarna hitam berbintik halus dan berserabut merupakan matrix perlit, sedangkan bagian yang berwarna putih berukuran besar merupakan primary carbide berukuran antara $5-20 \mu \mathrm{m}$, ukuran primary carbide pada spesimen $\mathrm{J} 1$ As-Received hampir sama dengan spesimen K1 As-Received. Bagian berwarna putih yang berukuran lebih kecil dari primary carbide merupakan secondary carbide berukuran 1-4 $\mu \mathrm{m}$.

Pada spesimen $\mathrm{J} 2$ treated, bagian yang berwarna hitam berbintik halus merupakan matrix martensit temper, yang mengelilingi primary dan secondary carbide sedangkan bagian yang berwara putih berukuran besar merupakan primary carbide berukuran antara 5-20 $\mu \mathrm{m}$. Bagian berwarna putih yang berukuran lebih kecil dari primary carbide merupakan secondary carbide, berukuran $1-4 \mu \mathrm{m}$, setelah proses perlakuan panas pada spesimen $\mathrm{J} 2$ treated terbentuk fine secondary carbide (small secondary carbide) dengan bentuk yang spherical (hampir bulat), halus, lebih kecil dari secondary carbide berukuran $\leq 2 \mu \mathrm{m}$.

Distribusi primary carbide dan secondary carbide pada spesimen J1 as-received seragam dan distribusi primary carbide pada spesimen $\mathrm{J} 2$ treated juga seragam dengan secondary carbide dan fine secondary carbide yang dikelilingi matrix martensit temper, distribusi karbida pada spesimen $\mathrm{J} 2$ treated merupakan perpaduan dari primary cabide yang terdistribusi merata dan terbentuknya newly fine secondary carbide yang halus dan banyak yang menjadi kelebihan yang dimiliki oleh spesimen $\mathrm{J} 2$ treated yang natinya dapat dihubungkan dengan pegujian lain, seperti pengujian aus sehingga dapat dibuktikan mengenai kelebihan dari sifat mekaniknya.

\subsection{Analisis Hasil Pengujian Kekerasan Micro-Vickers}

Pada pengujian kekerasan micro-vickers dilakukan indentasi (penekanan) pada spesimen as-received (annealed condition) dan treated (setelah proses perlakuan panas).

Tabel 14. Kekerasan Micro-Vickers As-Received

\begin{tabular}{cccc}
\hline Titik indentasi & C1 & K1 & J1 \\
\hline 1 & 293 & 300 & 272 \\
2 & 293 & 278 & 272 \\
3 & 285 & 297 & 251 \\
4 & 282 & 290 & 247 \\
5 & 268 & 290 & 270 \\
6 & 268 & 308 & 270 \\
7 & 298 & 308 & 270 \\
\hline AVERAGE (HVN) & $\mathbf{2 8 4}$ & $\mathbf{2 9 6}$ & $\mathbf{2 6 5}$ \\
\hline
\end{tabular}

Tabel 15. Kekerasan Micro-Vickers Treated

\begin{tabular}{cccc}
\hline Titik indentasi & C2 & K2 & J2 \\
\hline 1 & 757 & 696 & 739 \\
2 & 699 & 730 & 696 \\
3 & 673 & 710 & 705 \\
4 & 705 & 763 & 665 \\
5 & 745 & 694 & 696 \\
6 & 724 & 678 & 721 \\
7 & 688 & $\mathbf{7 0 2}$ & 686 \\
\hline AVERAGE (HVN) & $\mathbf{7 1 3}$ & $\mathbf{7 1 0}$ & $\mathbf{7 0 1}$ \\
\hline
\end{tabular}

Setelah proses perlakuan panas nilai kekerasan pada masing-masing spesimen mengalami peningkatan, spesimen C2 dan K2 memiliki nilai kekerasan tertinggi hal ini disebabkan karena primary carbide yang 
terbentuk merupakan karbida kasar dengan ukuran 20-60 $\mu \mathrm{m}$, dengan distribusi yang tidak seragam, sedangkan pada spesimen $\mathrm{J} 2$ memiliki nilai kekerasan terendah dibanding dengan spesimen $\mathrm{C} 2$ dan $\mathrm{K} 2$ yang disebabkan ukuran primary carbide yang lebih kecil 5-20 $\mu \mathrm{m}$ dengan fine-secondary carbide yang terdistribusi dengan merata. Perbandingan nilai kekerasan antara spesimen as-received dan treated, setelah proses perlakuan panas terjadi peningkatan nilai kekerasan yang sangat signifikan, nilai kenaikan kekerasan tertinggi diperoleh spesimen J2 treated, yaitu mengalami peningkatan kekerasan sebesar $436 \mathrm{HV}$ atau sebesar $62 \%$ sedangkan spesimen $\mathrm{C} 2$ dan $\mathrm{K} 2$ treated mengalami peningkatan kekerasan masing-masing sebesar $426 \mathrm{HV}$ dan $412 \mathrm{HV}$ atau masing-masing sebesar $60 \%$ dan $58 \%$.

\subsection{Analisis Hasil Pengujian Impak}

Pengujian impak dilakukan untuk megetahui ketangguhan pada masing-masing spesimen, setelah dilakukan pengujian diperoleh nilai impak seperti pada Tabel 16.

Tabel 16. Nilai Impak spesimen As-Received

\begin{tabular}{cc}
\hline \multicolumn{2}{c}{ As-Received } \\
\hline \multirow{2}{*}{ Kode Spesimen } & $\begin{array}{c}\text { V-Notch Charpy } \\
\text { Energy(Joule) }\end{array}$ \\
\hline C1 & 2.81 \\
K1 & 4.19 \\
J1 & 4.38 \\
\hline
\end{tabular}

Nilai impak pada spesimen as-received tertinggi dihasilkan dari spesimen J1 yaitu 4.38 Joules, spesimen tersebut lebih tangguh dari spesimen lainnya, karena memiliki secondary carbide yang relatif terdistribusi dengan merata.
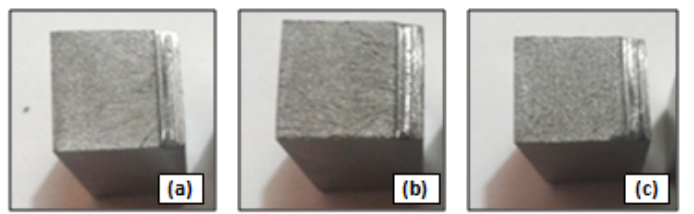

Gambar 17. Foto hasil patahan pada spesimen As-Received setelah pengujian impak (a) C1, (b) K1 dan (c) J1

Dari foto hasil patahan pada

Gambar 17, spesimen K1 dan J1 memiliki bentuk patahan berserat (fibrous) yang melibatkan mekanisme pergeseran bidang-bidang kristal. Setelah proses perlakuan panas, dilakukan proses pengujian impak untuk mengetahui perbedaan nilai impak sebelum dan sesudah proses perlakuan panas. Setelah dilakukan pengujian impak didapatkan hasil seperti pada Tabel 17.

Tabel 17. Nilai Impak spesimen Treated

\begin{tabular}{cc}
\hline \multicolumn{2}{c}{ Treated } \\
\hline Kode Spesimen & V-notch Charpy Energy (Joule) \\
\hline C2-IP & 3.53 \\
K2-IP & 3.63 \\
J2-IP & 2.35 \\
\hline
\end{tabular}

Nilai impak tertinggi dihasilkan pada spesimen C2 dan K2 masing-masing sebesar $3.53 \mathrm{~J}$ dan $3.63 \mathrm{~J}$, foto patahan dapat dilihat pada Gambar 18, hasil patahan pada spesimen C2 dan K2 merupakan patahan berserat (fibrous), sedangkan spesimen J2-IP memiliki patahan granular yang dihasilkan dari pembelahan butir yang getas.
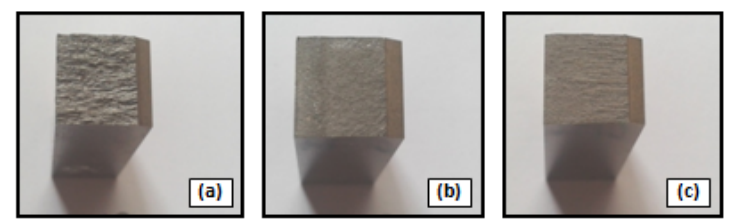
Gambar 18. Foto hasil patahan pada spesimen Treated setelah pengujian impak (a) C2, (b) K2 dan (c) J2

Terjadi penurunan harga impak yang cukup signifikan setelah proses perlakuan panas pada spesimen K2 dan $\mathrm{J} 2$ sedangkan spesimen $\mathrm{C} 2$ mengalami kenaikan harga impak sebesar $0.72 \mathrm{~J}$, sedangkan pada spesimen $\mathrm{K} 2$ dan $\mathrm{J} 2$ mengalami penurunan harga impak masing-masing sebesar $0.53 \mathrm{~J}$ dan $2.03 \mathrm{~J}$. Spesimen J2 merupakan spesimen dengan nilai impak terendah dan mengalami penurunan harga impak tertinggi setelah proses perlakuan panas.

\subsection{Analisis Hasil Pengujian Abrasi}

Pengujian abrasi dilakukan untuk mengetahui mass loss dan wear rate dari masing-masing spesimen sehingga dapat mengetahui ketahanan abrasi dari masing-masing spesimen. Setelah dilakukan pengujian abrasi sebanyak 4.500 putaran dengan beban sebesar 5,8 kg dan kecepatan putar 5,3 m/s menggunakan disc yang memiliki kekerasan sebesar 165 BHN.

Kecepatan putaran terendah dihasilkan oleh spesimen J2-WR yaitu $76.88 \mathrm{rpm}$, semakin rendah kecepatan putaran maka semakin tinggi ketahananya terhadap keausan, hal ini disebabkan karena secondary carbide pada spesimen tersebut relatif banyak dengan distribusi yang seragam, selain itu terbentuk newly fine secondary carbide yang terdistribusi dengan seragam yang berfungsi untuk menghalangi terjadinya gesekan (aus). Gambar 4 memperlihatkan spesimen yang telah dilakukan uji abrasi, pada gambar tersebut terlihat spesimen $\mathrm{C} 2$ mengalami bekas gesekan yang relatif lebih dalam dari spesimen lainnya, hal ini serupa dengan nilai mass loss dan kecepatan putar yang tinggi, spesimen C2 merupakan spesimen yang memiliki ketahanan aus terendah meskipun memiliki nilai kekerasan tertinggi dan nilai impak yang tinggi.

Spesimen C2 memiliki Mass Loss tertinggi, yaitu $0.000726 \mathrm{gr} /$ menit, meskipun memiliki nilai kekerasan tertiggi, yaitu $713 \mathrm{HV}$, hal ini disebabkan oleh distribusi primary carbide yang tidak seragam dengan jumlah yang sedikit dan terbentuk coarse primary carbide sehingga tidak mampu menghambat proses terjadinya gesekan (aus), selain itu karena ukuran primary carbide yang besar, sehingga mekanisme abrasi yang terjadi pada spesimen $\mathrm{C} 2$ adalah fragmentation, ukuran karbida yang besar memudahkannya terkelupas, dengan ukuran karbida yang besar maka setelah terkelupas, mass loss nya akan berkurang secara signifikan, sedangkan pada spesimen K2 dan J2 mengalami mass loss yang hampir sama yaitu 0.000439 $\mathrm{gr} / \mathrm{menit}$ dan $0.000381 \mathrm{gr} / \mathrm{menit}$, hal ini terjadi karena primary carbide dan secondary carbide yang terbentuk relatif seragam, sehingga mampu menghambat proses terjadinya gesekan (aus), meskipun spasimen K2 memiliki nilai mass loss yang hampir sama dengan spesimen J2, spesimen K2 memiliki nilai kecepatan putar yang lebih tinggi dari J2, sehingga jika dibandigkan, maka spesimen J2 merupakan spesimen yang memiliki mass loss yang rendah sekaligus kecepatan putar yang rendah, yaitu 0.000381 $\mathrm{gr} /$ menit sehingga menghasilkan ketahanan abrasi yang tertinggi.

Nilai kekerasan tidak bisa dihubungkan dengan ketahanan abrasi pada spesimen AISI D2, karena ketahanan abrasi pada spesimen AISI D2 dipengaruhi oleh ukuran dan bentuk karbida dan mekanisme terjadinya keausan abrasi, seperti terlihat pada struktur mikro penampang setelah dilakukan pengujian abrasi pada bagian spesimen yang mengalami keausan.

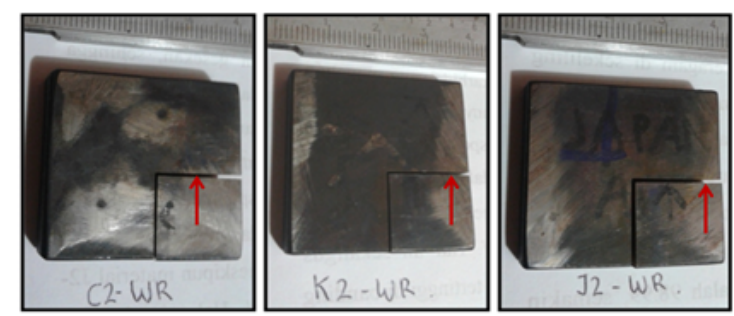

Gambar 19. Spesimen hasil pengujian aus

Karbida yang terbentuk pada spesimen C2 dan K2 ukurannya lebih besar Karbida yang terbentuk pada spesimen C2 dan K2 ukurannya lebih besar dan jumlahnya lebih sedikit dari pada spesimen J2, sehingga spesimen tersebut tidak dapat menahan terjadinya gesekan pada proses pengujian abrasi, nilai mass loss spesimen C2 adalah 0.0313 yang merupakan mass loss tertinggi diantara spesimen lainnya, artinya spesimen tersebut lebih mudah mengalami aus, hal ini diakibatkan oleh karbida yang dapat menahan gesekan hanya sedikit dan matrix martensit temper yang jumlah nya lebih banyak tidak mampu menahan gesekan, karena sifatnya yang lebih lunak dari karbida 
Spesimen K2 dan J2 memilkiki nilai mass loss yang hampir sama yaitu 0.0207 gr dan 0.0215 gr dan kecepatan putar masing-masing $98.88 \mathrm{rpm}$ dan $76.88 \mathrm{rpm}$. Pada struktur mikro K2 jumlah karbida yang dimiliki relatif banyak hampir sama dengan jumlah karbida pada spesimen J2, tetapi spesimen J2 memiliki primary carbide berukuran kecil $(5-25 \mu \mathrm{m})$, tidak terdapat coarse primary carbide dan terdapat fine secondary carbide yang lebih banyak dan seragam di sekeliling matrix martensit temper, yang berfungsi untuk menahan gesekan, sehingga struktur mikro cross section seperti terlihat pada gambar 5 pada bagian permukaannya relative rata, sedangkan pada bagian permukaan spesimen K2 lebih bergelombang karena terdapat coarse primary carbide yag berukuran $60 \mu \mathrm{m}$ dan karbida yang menahan gesekan hanya primary dan secondary carbide yang jumlahnya lebih sedikit dari spesimen J2. Hal ini setara dengan kecepatan putarnya, pada spesimen J2 kecepatan putar nya adalah $76.88 \mathrm{rpm}$ sedangkan spesimen K2-CS adalah 98.99 rpm, semakin kecil kecepatan putarnya semakin tinggi ketahanan ausnya, meskipun material J2 memiliki nilai kekerasan yang terendah yaitu $701 \mathrm{HV}$. Hal ini sekaligus membuktikan bahwa spesimen J2 memiliki ketahanan aus tertinggi di banding spesimen K2 dan C2.
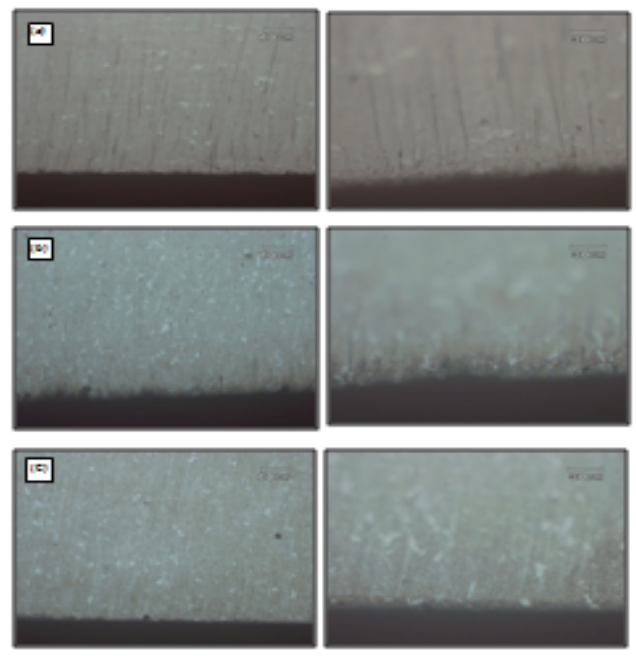

Gambar 20. a) struktur mikro cross section setelah proses pengujian aus (a) C2-CS, (b) K2-CS dan (c) J2-CS.

\section{Kesimpulan}

Berdasarkan hasil penelitian yang telah dilakukan, adapun saran untuk penelitian ini adalah sebagai berikut:

1. Melakukan variasi waktu pengadukan dan kecepatan pengadukan untuk melihat ada atau tidak pengaruh dari waktu dan kecepatan pengaduknya.

2. Perlu dilakukan peninjauan kembali apabila akan menggunakan koagulan untuk skala yang lebih besar, baik aspek lingkungan maupun biayanya.

3. Melakukan pengujian karakteristik dan muatan flok yang terbentuk saat flokulasi.

\section{Daftar pustaka}

[1] Singh, K., Kartikhar, K. R., Sapate, G. S., (2015) : Microstructure evolution and abrasive wear behaviour of D2 steel, J Wear, 328-329, 206-216.

[2] ASTM E.95. Metalography examination, edited by ASTM International, 2007.

[3] ASTM E.384. Micro Vickers, edited by ASTM International, 2007.

[4] ASM Vol. 10. Material Characterization 9 th Edition, USA : ASM International, 1992.

[5] ASTM E.23. Impact Test, edited by ASTM International, 2007.

[6] JIS, Japan Industrial Standard, JIS G 4404 alloy tool steels, ICS.25.100.01;77.140.35, 2006.

[7] Analytical workshop, centre of microscope and analysis, CMA, 2012

[8] Microstructure and mechanical properties of AISI D2 steel after bright hardening and oil quenching, J.Materials and design, 54, 1049-1055. 